\title{
Trajetórias de vida: \\ desafios da pesquisa sociourbanística e contribuição para a gestão pública
}

\section{Life trajectories: challenges to the socio-urbanistic research and contribution to administration}

\author{
Frederico Ramos* \\ Dirce Koga**
}

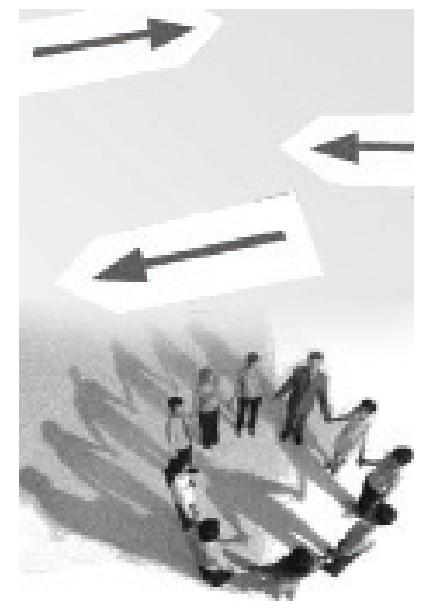

Resumo: Apoiando-se em trabalhos que utilizaram as técnicas de pesquisa qualitativa de história de vida e análise de trajetórias em diferentes campos disciplinares, o texto procura refletir sobre as possibilidades e limitações da aplicação destas técnicas na incorporação da dimensão relacional do território na definição de políticas públicas e no campo da pesquisa sociourbanística. Aqui, o (re)conhecimento sobre as trajetórias de vida dos chamados "usuários" das políticas públicas poderia representar uma chave importante para processos da gestão pública onde os cidadãos encontrem-se na centralidade do interesse e prevaleça a conexão indivisível entre os campos urbano e social.

Palavras-chave: Urbanismo. Histórias de vida. Análise de trajetória. Políticas públicas. Território.

\begin{abstract}
Drawing on studies that used qualitative research techniques of life history and trajectory analysis in different disciplines, the text attempts to reflect on the possibilities and limitations of these

* Frederico Ramos é arquiteto urbanista, mestre em Sensoriamento Remoto pelo Inpe, doutorando da Fundação Getúlio Vargas em Administração Pública e Governo, pesquisador assistente do Cepesp/FGV Centro de Estudos de Política e Economia do Setor Público e pesquisador do Cedest - Centro de Estudos das Desigualdades Socioterritoriais (Inpe/PUC-SP), Brasil. E-mail: fred.r.ramos@gmail.com.

** Dirce Koga é assistente social, doutora em Serviço Social pela PUC-SP, professora titular do Programa de Mestrado de Políticas Sociais da Universidade Cruzeiro do Sul - São Paulo, Brasil, pesquisadora do Cedest — Centro de Estudos das Desigualdades Socioterritoriais (Inpe/PUC-SP).E-mail: dirce.koga@ uol.com.br.
\end{abstract}


techniques in the incorporation of the relational dimension of territory in the definition of public policies and in what we called "sociourbanistic" research. Here, the knowledge about the ways of life of so-called "users" of public policy could represent an important key to locate the citizens on the centrality of the processes in public administration, creating conditions to the prevalence of the inseparable connection between the urban and social fields.

Keywords: Urbanism. Life histories. Trajectory analysis. Public policies. Territory.

\section{Introdução}

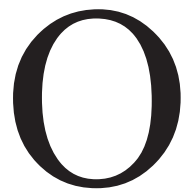

texto propõe debater sobre a dinâmica socioterritorial e os desafios de sua apreensão pelas técnicas de pesquisa, no sentido de favorecer uma leitura mais próxima do cotidiano vivido pelas populações em seus territórios. Este trabalho nasce de uma inquietação dos autores em relação ao distanciamento percebido em processos de construção do conhecimento sobre as cidades, evidenciando um distanciamento entre as abordagens urbana e social. Ora pendendo para um ou outro campo, as cidades surgem como cenários representativos de situações específicas que parecem estanques, soltas no tempo e no espaço. Uma das formas dessas representações tem sido a utilização de indicadores sociais e urbanos que buscam expressar determinadas características dos territórios analisados nas suas diferentes escalas.

Sabemos que os indicadores exercem um papel importantíssimo na construção de instrumentos de leitura da realidade, porém ao mesmo tempo identificamos seus limites quanto à representação dessa realidade, especialmente quanto à sua dinâmica interna, o seu cotidiano repleto de variações que tendem a ser homogeneizadas sob a forma de índices sintéticos, por exemplo.

Nessa direção, tem nos chamado a atenção estudos sobre cidades que têm tomado como referência a história de vida e a análise de trajetórias. Estas técnicas foram recentemente utilizadas em dois estudos sobre a cidade de São Paulo, no início do século XXI, e procuraram revelar, a partir da narrativa de indivíduos, trajetórias urbanas por meio do olhar específico sobre a cidade e as relações que seus habitantes estabelecem com ela. Essas técnicas tiveram sua gênese na Escola de Chicago nos anos 1920, momento de surgimento da cidade moderna, e sua aplicabilidade para a pesquisa sobre as cidades tem sido reafirmada até os dias atuais. 
Este trabalho discute a aplicabilidade dessas técnicas como estratégia de integrar as perspectivas urbana e social enquanto interfaces da dinâmica socioterritorial, um modo de olhar para a realidade e buscar compreendê-la nessa interface de campos distintos, porém partes da mesma totalidade de apreensão. Para tanto, o texto vai buscar nas técnicas de história de vida e trajetórias um caminho em que os campos urbano e social se encontrem, e onde as possibilidades para uma gestão pública mais conectada com essa interface se mostrem mais factíveis.

\section{Dinâmica socioterritorial e a pesquisa sociourbanística}

Em seu artigo intitulado "A cidade: objeto de estudo e experiência vivenciada", a historiadora Maria Stella Bresciani (2004) introduz uma discussão sobre a cidade atual e os alcances e limitações do urbanismo apoiada nas reflexões de Guilio Carlo Argan (1993). Trata-se de analisar o urbanismo que, segundo Argan, se encontra hoje em uma "preocupante ambiguidade metodológica". As cidades que atualmente abrigam mais da metade da população mundial são infelizmente exemplos do que ele chamou de "ambientes repressivos e alienantes". Na relação entre cultura e poder, expressa em cada solução urbanística, o poder em geral tem prevalecido. Para Argan, tal situação decorre de um processo de transformação sucessiva do projeto arquitetônico em programação urbanista e, correlatamente, em industrialização das construções que se acelera e amplia a cada ano. Hoje o urbanismo entrelaça-se estreitamente com o planejamento econômico, estudo dos sistemas de comunicação que trata basicamente da coordenação dos diversos aglomerados sociais. Ele diz:

Arte ou ciência, economia, sociologia, política, tecnologia: onde localizar esse saber cujo objeto parece se impor de maneira tão óbvia ao olhar? Nem arte como as cidades concebidas como uma única e grande arquitetura pelos teóricos da Renascença -; nem ciência, atrelada a um conjunto de leis objetivas e constantes; nem o momento prático da sociologia, da economia ou da política, pois aplicáveis sob o aspecto da tecnologia. O urbanismo não se conformaria ao perfil de nenhuma dessas disciplinas. (Argan, 1993, p. 211)

Se reconhecermos que de fato há esta "ambiguidade metodológica" no pensamento urbanístico, devemos estar atentos a estudos que de alguma for- 
ma podem apontar perspectivas na sua superação. Em contraponto, e na mesma direção ambígua, observamos que no campo social as condições de vida das populações aparecem descoladas de seus respectivos chãos, tendendo a uma homogeneização das situações analisadas, ou ainda a uma categorização no formato de "públicos-alvos": pessoas com deficiência, famílias pobres, população de rua, idosos abandonados. Enfim, situações que parecem deslocadas das dinâmicas socioterritoriais individuais e coletivas às quais são parte intrínseca.

Em 1992, Marc Augé (1994) cunhou o termo "antropologia da supermodernidade". Sua linha de argumentação partiu da caracterização da supermodernidade, situação na qual vivemos nas cidades hoje, a partir de três figuras do excesso: a superabundância factual, a superabundância espacial e a individualização das referências. Estes estados de excessos marcados pela velocidade, simultaneidades e exagero informacional requerem, o que segundo ele mesmo definiu, uma postura antropológica em sua análise. Essa postura tem em sua componente espacial o que ele define como lugar antropológico.

Em suas palavras, “um lugar que é antes geométrico, trata-se da linha, da interseção das linhas e do ponto de interseção. Itinerários, eixos ou caminhos que conduzem de um lugar ao outro e foram traçados pelos homens e, por outro lado, em cruzamentos e praças onde os homens se cruzam". O lugar antropológico "é simultaneamente princípio de sentido para aqueles que o habitam e princípio de inteligibilidade para quem o observa" (Augé, 1994, p. 39).

Da perspectiva que Augé nos coloca deriva a necessidade de estabelecimento de um instrumental analítico capaz de capturar e representar esses lugares que se pretendem indentitários, relacionais e históricos. Neste sentido, baseando-se na terceira figura de excesso definida por Augé: a individualização das referências, a análise deveria permitir o trânsito entre diferentes escalas, da individual para a coletiva, já que como ele mesmo diz, "nunca as histórias individuais foram tão explicitamente referidas pela história coletiva, mas nunca, também, os pontos de identificação coletiva foram tão flutuantes" (Augé, 1994, p. 39).

Recente trabalho intitulado Questions sociales et questions urbaines, de Julien Damon (2010), a partir de suas pesquisas envolvendo as temáticas da pobreza e da cidade, busca abordar o que ele chama "essas duas famílias de 
questões" uma série de chaves que se encontram imbricadas nas questões societárias em um mundo urbanizado. Trata-se de um esforço do pesquisador em abordar as questões sociais e urbanas de forma imbricada em um cenário cada vez mais urbanizado.

Para Maria Stella Bresciani (2004), há necessidade de introdução de novos referenciais analíticos tanto no campo urbanístico como social. Sua pesquisa é dedicada à questão da cidade enquanto objeto de estudo e experiência vivenciada. Para ela, "estudar a(s) cidade(s) implica estabelecer conexões de tipo variado com a própria experiência de viver em cidades" (Bresciani, 2004, p. 9).

Bresciani aponta em sua pesquisa questões que situam no eixo central da análise as relações entre o especialista e o citadino, entre projeto e realização, entre intenção e resistência. Essas questões estabelecem outros centros de massa aos pensamentos urbanístico e social, discutindo a participação e a cumplicidade com a formação das cidades. Sua contribuição é relevante na medida em que abre, a partir de uma perspectiva interdisciplinar, chaves para a superação do esquematismo condenado por Argan que ainda prevalece no urbanismo. Novamente a questão do indivíduo é colocada em evidência a partir de um questionamento estabelecido pelo próprio Argan e citado pela autora:

Mas o que de fato aconteceu na cidade moderna? Ora, para Argan, isto, sem dúvida, se deve em grande parte à redução do valor do indivíduo, do ego; o indivíduo não é mais do que um átomo na massa. Elimina-se com esse valor o valor da história de que o ego é o protagonista, e eliminar o ego como sujeito corresponde a eliminar a natureza. A realidade não é mais dada em escala humana, isto é, na medida em que pode ser concebida, pensada, compreendida pelo homem. (Bresciani, 2004, p. 10)

A discussão apoiada em Argan avança rumo à constituição de uma argumentação onde seria decepcionante e ineficaz a tentativa de projetar a cidade para um futuro que não nos pertence. Para ele, o urbanismo é "programação e projeto", projeto que se "inicia na forma de componente científico, pois efetua análises rigorosas sobre a condição demográfica, econômica, produtiva, sanitária, tecnológica dos agregados sociais; soma em seguida os componentes sociológico, político e histórico, já que estuda as estruturas sociais e seus pos- 
síveis desenvolvimentos; faz depois opções tanto sobre a orientação a tomar, pondo em perspectiva passado e futuro, como sobre o estético, por determinar as estruturas formais. São dados, explica, que não devem ser combinados, porém resultar em algo próprio ao trabalho do urbanista: o plano. Por exemplo, o "plano diretor", que precisa ser encarado em sua finalidade de orientar e não ser imposto ou traduzido em realidades construtivas.

Assim, a questão do "valor estético da cidade" prevalece, a cidade é experiência sensorial a qual seus habitantes atribuem valor e significado. Esta linha de argumentação persegue a reaproximação do indivíduo enquanto sujeito, da dimensão humana e cidadã que é a própria fundadora da noção de cidade.

Detendo-nos na perspectiva da cidade e na constituição de seu valor estético formatado a partir das experiências conscientes e inconscientes de seus habitantes, emerge a questão que motivou a elaboração deste trabalho: como capturar tais dimensões de modo a compor o universo analítico necessário aos ofícios do urbanista e do trabalhador social dentro da perspectiva que nos coloca Argan e Augé? Certamente isso exigirá a apropriação de métodos de investigação que consigam, ao menos em parte, representar o emaranhado de percursos e práticas individuais e coletivas que constituem a noção fundadora de cidade.

Neste sentido, não há como escapar da afirmação de Argan sobre a necessidade de uma análise que se baseie no "estudo da experiência urbana individual como princípio de qualquer pesquisa sobre os modos de vida urbana de uma sociedade real" (Argan, 1993).

Tratando do debate da exclusão social em cidades brasileiras, os geógrafos Everaldo Melazzo e Raul Guimarães (2010) também irão destacar a importância de se elucidar os vínculos entre território e desigualdades sociais, tendo como cenário as condições objetivas e subjetivas das trajetórias das exclusões sociais, conforme trecho a seguir: "As imbricações entre as exclusões sociais e as dinâmicas territoriais urbanas podem ser apreendidas por vários caminhos, desde aquelas que tratam de definir os diferentes lugares onde se materializam situações específicas de exclusão, até aquelas que buscam, na própria produção do território, as condições objetivas e subjetivas das exclusões sociais" (Melazzo e Guimarães, 2010, p. 23). 
Obviamente, há nas discussões apresentadas uma preeminência em colocar o sujeito social no centro das análises urbanísticas. Tal orientação tem sido aplicada em outros campos das ciências humanas, como pudemos observar na própria Geografia. De fato, como aponta Montagner (2007, p. 242), "esta inflexão, nomeada por muitos retorno do sujeito, tem raízes bastante profundas nas sociedades modernas, para muitos, pós-modernas. Sem assumirmos as teorias pós-modernas, que propõem uma ruptura radical no decurso histórico e exacerbam as características inauditas da sociedade de informação, devemos admitir, ao menos, uma exacerbação das transformações históricas do capitalismo". No contexto analítico proposto por Augé, faz sentido que essas transformações reverberem em vários campos do conhecimento. Entretanto, se assumimos, como Argan advoga, que o urbanismo vive uma preocupante ambiguidade metodológica, tal orientação passa se constituir linha de base da análise urbanística na sua imbricação com o campo social, o que propomos tratar-se de uma análise sociourbanística.

Como uma das expressões do direcionamento da análise sociológica ao sujeito social, tem se disseminado a utilização de técnicas conhecidas como "História de vida" e "Análise de trajetórias". Esses métodos têm sua origem associada a pesquisas etnológicas, entretanto isso não tem impedido que outros campos do conhecimento utilizem essas técnicas em aplicações diversas. Em urbanismo, a aplicação dessas técnicas tem ganhado um contorno particular em virtude da proeminência da dimensão espacial característica da disciplina. Seja qual for o campo de aplicação e sua motivação, alguns estudos têm tratado especificamente a técnica de história de vida e análise de trajetória discutindo desde seus aspectos procedimentais às limitações inerentes a sua aplicação. A próxima seção apresentará alguns destes trabalhos, procurando introduzir o debate da aplicação desses métodos na análise sociourbanística na seção final.

\section{Conexões entre a dinâmica urbana e as trajetórias de vida na pesquisa sociourbanística}

Um dos principais aspectos a serem considerados para a compreensão do uso que se faz em análises baseadas em histórias de vida é que, em última ins- 
tância, não estamos interessados na história de um indivíduo. Por mais paradoxal que isto possa parecer, estamos interessados no que as experiências de vida desse indivíduo podem revelar a respeito de determinado objeto de pesquisa sobre o qual temos interesse. Buscamos com essa técnica revelar como operam sobre esse indivíduo os processos sociais nos quais ele está inserido, quais são suas redes sociais e o potencial significado na conformação da identidade de determinado grupo social. Neste sentido, há poucas alternativas ao uso deste método. A profundidade exigida para uma investigação dessa natureza acaba por definir uma estratégia de aproximação gradual de reconstituição de trajetórias de vários indivíduos.

A literatura trata desse aspecto fundamental do uso da história de vida reiteradamente definindo o indivíduo como representante de um determinado grupo social. Em seu trabalho denominado "História de vida", Oracy Nogueira (1975, p. 139) enfatiza a utilidade desta técnica para a sociologia quando diz que

os documentos íntimos constituem importante fonte de dados para o sociólogo. Através deles (obtidos oralmente ou por escrito), o sociólogo descobre a concepção que o indivíduo tem de seu papel e de seu status nos vários grupos de que é membro. Através dos documentos pessoais ele muito aprende sobre os aspectos subjetivos da cultura e da organização social, das instituições e movimentos sociais.

Vale lembrar que Oracy Nogueira foi um dos sociólogos e antropólogos brasileiros de destaque, no final dos anos 1940 e décadas seguintes, que entre suas influências teóricas conta com a Escola de Chicago. Esta foi a primeira escola a exercer influência sobre as pesquisas urbanas e é nela que se estabelece o conceito de sociologia urbana.

No Brasil, a Escola de Chicago influenciou trabalhos tais como os de relações raciais (negros, brancos e imigrantes), como os das categorias de aculturação e assimilação, os estudos de comunidade que tiveram grande importância não só no Brasil como em outros países do mundo, com uma preocupação nas migrações campo-cidade, principalmente em três campos: a) no das relações raciais, b) no dos clássicos estudos de comunidade e c) nos estudos precursores na cidade de São Paulo (Mendoza, 2005). 
Neste contexto acadêmico, o relato da experiência individual já se tornara um instrumento para o conhecimento do indivíduo como agente humano participante da vida social. São inúmeras as referências a trabalhos como de John Dollard (1935, apud Nogueira, 1975), cientista social da Universidade de Chicago, que apontava a utilização da história de vida como método analítico por privilegiar "o estudo das representações numa tentativa deliberada para definir o desenvolvimento de uma pessoa num meio cultural e lhe dar sentido teórico". Como um dos pioneiros na utilização de histórias de vida para fins científicos, Dollard enumera alguns critérios a serem observados na sua aplicação:

- O pesquisado deve ser visto como um exemplar dentro de um contexto cultural. As atitudes e o comportamento do entrevistado devem estar relacionados com o conhecimento da cultura e a organização social na qual ele está inserido.

- Os motivos orgânicos atribuídos à ação devem ser socialmente significativos. Há que se verificar o significado atribuído pelo grupo às características físicas e fisiológicas apresentadas pelo indivíduo.

- O papel peculiar da família na transmissão da cultura deve ser reconhecido. A família é o núcleo socializador por excelência. Devem-se reconhecer os aspectos mais relacionados à esfera íntima do indivíduo.

- O método específico de transformação de condições orgânicas em comportamento social deve ser mostrado. Aqui surge novamente a importância da situação social e cultural que acaba por definir as formas como o indivíduo busca satisfazer seus impulsos e necessidades.

- $\mathrm{O}$ aspecto de continuidade da experiência, da infância à maturidade, deve ser patente.

- A situação social deve ser cuidadosa e continuamente especificada como um fator. Muitas manifestações peculiares da personalidade do indivíduo estão relacionadas a experiências e incidentes críticos vivenciados por ele.

- O próprio material da história de vida deve ser organizado e conceitualizado. Há sempre que se fazer uma análise sobre o material coletado para estabelecer o que deve ser incluído ou retirado, o que é re- 
levante para a análise em função do interesse específico que a pesquisa apresente.

Esse conjunto de recomendações forma a base procedimental da técnica de história de vida e análise de trajetórias e reforça a noção de indivíduo como sujeito social. Nogueira apoia-se nesta concepção e define história de vida como o "relato da experiência individual que revela as ações do indivíduo como agente humano e como participante da vida social". Neste sentido, a análise se constitui a partir de um conjunto de relatos de indivíduos representativos de um grupo ou segmento social sobre o qual se tem interesse. Deste conjunto de informações surge um mosaico de relatos a partir do qual se estabelecem as formulações a respeito dos processos e ações sociais que caracterizam o grupo.

A observação desses procedimentos estabelece as precondições para utilização da história de vida em pesquisa científica. De fato, essa técnica foi introduzida no meio acadêmico pela Escola de Chicago por sociólogos como Ernest Burgess (1935, apud Nogueira, 1975, 139) que entendia que "tal como um microscópio, ela (a história de vida) habilita (a quem investiga a personalidade) a ver em condições de aumento e em detalhe a interação total dos processos mentais e relações sociais".

A contribuição de Burgess (1925) para a sociologia urbana é reiteradamente afirmada a partir de referências ao modelo de expansão urbana baseado em zonas concêntricas desenvolvido para Chicago em 1925. Nesse modelo, o processo geral de expansão no crescimento urbano compreende os processos antagônicos de concentração e descentralização, além da extensão e sucessão. Foi na perspectiva de compreender o que ele chamou de "descentralização centralizada" que marcava o desenvolvimento de Chicago dos anos 1920, que ele aplicou a técnica de histórias de vida com o propósito de entender os processos de "desorganização e reorganização comunal" dos núcleos conurbados que se formavam com o intenso crescimento da cidade. O cenário da introdução da história de vida em pesquisa é a cidade moderna nascente, Chicago dos anos 1920, lugar de frenética evolução tecnológica e intensos fluxos migratórios. Burguess (1925, p. 25-26) descreve este cenário:

A Chicago de ontem, um aglomerado de pequenas cidades campestres e de colônias de imigrantes, está passando por um processo de reorganização num sistema 
centralizado-descentralizado de comunidades locais fundidas em subáreas comerciais visível ou invisivelmente dominadas pela zona central de comércio. [...] Os processos de expansão, e especialmente o ritmo de expansão, podem ser estudados não só no crescimento físico e no desenvolvimento comercial, mas também nas mudanças resultantes na organização social e nos tipos de personalidade. Até que ponto o crescimento da cidade, em seus aspectos físicos e técnicos, se acha emparelhado com uma reacomodação natural, mas adequada, na organização social?

Esse contexto exigiu a concepção do método analítico que permitisse uma aproximação ao fenômeno inédito, desconhecido em grande parte, um processo de reorganização social profunda que se constituía junto com as grandes aglomerações humanas modernas.

Estes exemplos evidenciam que os relatos registrados sobre as trajetórias individuais devem estar orientados para a análise da organização social e o papel do indivíduo. Trata-se de um processo de procura constante de "fios da meada" orientado para o foco da análise, e não simplesmente uma narrativa sequencial de acontecimentos. Desde sua gênese na Escola de Chicago, a utilização do método ganhou outras possibilidades, tendo se tornado uma preocupação para vários autores uma delimitação mais precisa de seu alcance e limitações para pesquisas científicas.

No campo da sociologia brasileira, destaca-se o trabalho de Maria Isaura Pereira de Queiroz (1991) — Variações sobre a técnica de gravador no registro da história viva - em cuja introdução sugestiva intitulada "Relatos orais: do indizível ao dizível" vai traçar a revalorização do relato oral, dentro do qual se situa a história de vida. Para a autora,

Nenhuma sociedade é um todo monolítico; em seu interior coexistem grupos e camadas sociais de diversos tipos, divisões por sexo e idade, coletividades variadas. Histórias de vida de indivíduos com posições diferentes dentro de um grupo, quer sejam membros da mesma família (como já colhera Oscar Lewis), quer se trate de homens e mulheres, quer diga respeito ao contraste entre os mais velhos e os mais jovens, servem para dirimir dúvidas e aprofundar conhecimentos. (Queiroz, 1991, p. 19)

Regina Weber (1996) dedica um artigo onde procura "comparar os procedimentos de que lança mão historiadores com aqueles empregados por, princi- 
palmente, sociólogos e antropólogos”. Ela se apoia em estudo de Micaela di Leonardo (1987) que discute essa questão e organiza uma lista de aspectos que diferenciam o trabalho antropológico do trabalho do historiador oral. Os principais pontos enumerados são:

- As entrevistas em história dirigem-se a indivíduos, enquanto o trabalho etnográfico toma por contexto um grupo de pessoas.

- Os historiadores orais buscam informações na narrativa e em artefatos, os etnógrafos na narrativa em combinação com o comportamento.

- O trabalho de campo é próprio do antropólogo, enquanto o documento oral é visto com suspeita por alguns historiadores.

- O material da história oral destina a ser de conhecimento público, a etnografia resguarda a privacidade de seus informantes.

- O historiador oral trabalha com a perspectiva intracultural e relativa ao passado, o antropólogo com a perspectiva intercultural e relativa ao presente. (Weber, 1996, p. 164)

Esses pontos permitem delimitar claramente o universo de aplicação da técnica de história de vida, diferenciando-a de uma perspectiva historicista. É, portanto, instrumento de pesquisa etnográfica, que se estrutura a partir de entrevistas abertas e observação direta em campo, interessado no momento presente, no entendimento das trajetórias individuais e coletivas capazes de explicar situações e comportamentos atuais de determinado segmento social.

O processo de aquisição de dados na análise de história de vida passa necessariamente pela aplicação de entrevistas narrativas em profundidade. As entrevistas devem ser conduzidas de modo a permitir que o informante revele dados de sua vida, o que exige, por parte do entrevistador, técnica e sensibilidade. Além disso, há que se ter sempre em foco os aspectos relevantes à análise, ou seja, não se trata apenas ouvir as histórias de vida, mas sim de encontrar formas de captar as narrativas que contribuam para o objeto de análise que se tem interesse e do qual aquele indivíduo é ou foi participante.

Uma vez que o método de análise é baseado em entrevistas, há que se observar as situações propícias à aplicação dessa técnica. A forma de abordagem, a postura do entrevistador diante do entrevistado, a linguagem, esses são 
preocupações que devem estar presentes em qualquer tipo de entrevista. Como recomendações gerais, Oracy Nogueira preconiza que em história de vida alguns pontos devem ser necessariamente observados:

- O relato feito pelo pesquisado deve ser suplementado por dados obtidos em outras fontes, tais como certidões, registros administrativos.

- O documento deve ser escrito nas próprias palavras do pesquisado (autobiografia ou registro textual de uma narração oral).

- O documento deve representar uma expressão livre, espontânea e detalhada das experiências passadas, das aspirações presentes e dos planos para o futuro.

- Um documento assegurado numa situação favorável em que as tendências ao engano ou ao preconceito sejam eliminadas ou reduzidas ao mínimo. (Burguess, 1931, apud Nogueira, 1975, p. 143)

São recomendações a serem observadas na aplicação da técnica para fins científicos. Entretanto, em muitos casos os níveis de atendimento a elas é parcial em virtude do contexto, ou seja, há desafios que se colocam no momento de sua aplicação, e por esse motivo é fundamental que todo o processo esteja documentado com o maior nível de detalhes possível para que se possa compreender os limites inerentes a cada uma das aplicações.

Regina Weber destaca algumas situações desafiadoras para a aplicação dessa técnica. A primeira diz respeito ao acesso aos informantes, apontando duas situações diversas: uma na qual os informantes localizam-se em redutos, guetos ou enclaves, nos quais a possibilidade de entrada é muitas vezes um complicador; outra na qual o objeto de análise é composto por indivíduos que se encontram espacialmente dispersos. Esses aspectos estão diretamente relacionados à territorialidade do objeto de análise. Em análises sociourbanísticas, a dimensão territorial já é em si constituinte do objeto, ou seja, interessa saber a forma como se dá a relação espaço-indivíduo na perspectiva relacional, identitária e histórica como definido por Augé. Portanto, mais do que considerar o território a partir da operacionalidade da pesquisa em termos de acesso a entrevistados, ele em si deve configurar objeto da análise. Discutiremos este ponto mais adiante.

Ainda trabalhando a dimensão operacional da técnica, a autora identifica uma segunda situação desafiadora que se apresenta no momento de aproxima- 
ção aos informantes e na explicitação dos objetivos da pesquisa. Muitas vezes, a fim de romper com a situação de estranhamento e desconfiança, os pesquisadores acabam justificando sua pesquisa dizendo que estão escrevendo um livro ou elaborando um estudo para a universidade. Entretanto, muitas vezes estas categorias estão bem distantes da realidade deste grupo de indivíduos, e a possibilidade de aproximação depende fundamentalmente das relações pessoais que o pesquisador consegue estabelecer. Como a própria autora afirma,

a dificuldade de compreender a pesquisa acadêmica, aliada a expectativa que a presença de uma pessoa de classe superior motiva, pode justificar dois comportamentos bastante recorrentes entre entrevistados de camadas menos privilegiadas. Por um lado, duvidam de atividades que não apresentem resultados práticos; de outro, passam a ver no entrevistador a figura redentora, um representante das autoridades governamentais que poderá aliviá-los das difíceis condições de vida que estão sendo, por isso mesmo, avaliada. (Weber, 1996, p. 164)

Neste sentido, há quem advogue, como o caso de Michel (1987, apud Weber, 1986), que a aplicação da observação participante é a única forma possível de superar esse hiato entre desiguais. De fato, a distância social é colocada como uma barreira que pode interferir negativamente e pode acabar invalidando a pesquisa para fins científicos.

Preocupado com essas potenciais interferências negativas, Burgess (1930, apud Nogueira, 1975) estabeleceu uma hierarquia de possíveis situações de poder e submissão que ocorrem entre entrevistado e entrevistador e que, mesmo que não possam ser consideradas em seu sentido literal, ajudam a ilustrar comportamentos e suas implicações à pesquisa. A escala vai de uma situação de punição e inquérito até uma situação de pesquisa onde se constituiria uma relação científica entre pesquisador e informante motivados pela sua contribuição de seu conhecimento à ciência. Provavelmente, os trabalhos se darão em alguma faixa intermediária dessa escala. $\mathrm{O}$ importante é estar atento às potenciais interferências que a situação do encontro pode provocar.

Se por um lado as perspectivas de aplicação de história de vida e análise de trajetória se mostram promissoras, pois permitem a aproximação analítica ao contexto social e o papel do indivíduo como nenhuma outra, há também autores que adotam uma postura crítica quanto à aplicação dessa em determi- 
nados contextos. Dentre eles destaca-se Pierre Bourdieu (1996), que dedicou um trabalho ao que ele definiu como risco da "ilusão biográfica", que pode levar ao fracasso da análise do processo social.

\begin{abstract}
A análise crítica dos processos sociais mal analisados e mal dominados que atuam, sem o conhecimento do pesquisador e com sua cumplicidade, na construção dessa espécie de artefato socialmente irrepreensível que é a "história de vida" e, em particular, no privilégio concedido à sucessão longitudinal dos acontecimentos constitutivos da vida considerada como história em relação ao espaço social no qual eles realizam, não é em si mesmo um fim. Ela conduz à construção da noção de trajetória como séries de posições sucessivamente ocupadas por um mesmo agente (ou mesmo grupo) num espaço que é ele próprio um devir, estando sujeito a incessantes transformações. Tentar compreender uma vida como uma série única e por si suficiente de acontecimentos sucessivos, sem outro vínculo que não a associação a um "sujeito" cuja constância certamente não é senão aquela de um nome próprio, é quase tão absurdo quanto tentar explicar a razão de um trajeto de metrô sem levar em conta a estrutura da rede, isto é, a matriz das relações objetivas entre as diferentes estações. (Bourdieu, 1996, p. 189)
\end{abstract}

Para Bourdieu, a noção de campo social é essencial na aplicação da análise de trajetórias. Fugir do risco das ilusões biográficas requer, portanto, a delimitação dos indivíduos em relação ao seu campo social, aproximando a abordagem mais de uma perspectiva das trajetórias de grupos de indivíduos através dos diferentes campos sociais. É a partir dela que se pode dar sentido à interpretação das trajetórias percorridas por indivíduos ou grupos de indivíduos na análise sociológica.

Ainda que em muitos casos a definição da análise de trajetórias se confunda com a história de vida, a partir da argumentação de Bourdieu a primeira ganha um significado mais específico, incorporando noções de contexto social que reforçam as especificidades da técnica. Entretanto, há na literatura diferenças conceituais e metodológicas sobre análise de trajetórias, sendo por vezes aplicada sob uma perspectiva mais objetiva de mobilidade social, e outra, mais subjetiva, relacionada à constituição das formas identitárias individuais. Dubar (1998) discute essas duas perspectivas por meio de suas especificidades metodológicas e também suas limitações. Sob seu ponto de vista, igual atenção deve 
ser dada às categorias institucionais, determinando "posições objetivas" (escolares, profissionais...), e às categorias de linguagem utilizadas por indivíduos em situação de entrevista de pesquisa.

Sob a perspectiva da "trajetória objetiva", a dificuldade inerente passa pelo estabelecimento das categorias sob as quais se procura reagrupar a multiplicidade de itinerários, demarcando posições sucessivas em uma abordagem longitudinal. O risco aqui é incorrer em uma análise "objetivista" das trajetórias em que não se leva em conta o sentido subjetivo que os indivíduos atribuem ao próprio percurso. Neste sentido, a análise seria necessariamente redutora, uma vez que a posição, num dado momento, é medida apenas numa escala apenas. É a relação entre as posições sucessivas que importa no modelo, e não cada posição isolada.

No outro extremo da argumentação de Dubar localiza-se a noção de "trajetória subjetiva", que busca, a partir da análise semântica das entrevistas, estabelecer as formas identitárias e os motivos pelos quais o sujeito está numa situação em que ele mesmo está se definindo, a partir de acontecimentos passados, aberto para determinado campo de possibilidades, mais ou menos desejáveis e mais ou menos acessíveis.

Seja sob a perspectiva mais ou menos objetiva ou subjetiva, a análise de trajetória se configura como técnica privilegiada para a compreensão de processos sociais que provavelmente não seriam alcançados por outra técnica analítica. A capacidade de revelar as estruturas mais profundas de determinado contexto social a partir da própria autodeclaração dos indivíduos que o compõem é a fortaleza desse método, que, como qualquer outro, também apresenta limitações e exige postura crítica do pesquisador em sua aplicação.

Entretanto, desde os primeiros estudos onde essa técnica foi utilizada no início do século XX até hoje, há uma primazia em sua aplicação em contextos urbanos. Ademais, sua aplicação tem se intensificado em análises dessa natureza nos últimos anos, tendo sido recorrentemente aplicada ao estudo de ambientes urbanos de cidades brasileiras. Na próxima seção apresentaremos dois importantes estudos que se utilizaram dessa técnica para o caso da cidade de São Paulo. São eles o trabalho de Vera Telles e Robert Cabanes (2006) e Lucio Kowarick (2009). Entendemos que, além das contribuições específicas à sociologia, esses trabalhos apontam para uma potencial contribuição ao urbanismo, 
hoje carente de uma reflexão mais profunda na perspectiva de superação da "ambiguidade metodológica" preconizada por Argan.

\section{Trajetórias de vida e pesquisas sociourbanísticas}

A cidade de São Paulo do início do século XXI é o cenário dos dois instigantes trabalhos baseados em análise de trajetórias e história de vida, no qual nos apoiaremos para discutir suas possíveis contribuições ao urbanismo. Ambos trazem uma clara delimitação espacial do contexto analítico. Entretanto, esses espaços delimitados são frequentemente extrapolados na análise em suas inter-relações funcionais e simbólicas com a cidade. Telles, Cabanes e sua equipe de pesquisadores circunscrevem a aplicação de suas entrevistas a duas áreas periféricas da cidade. A zona sul — área com marcada presença de ocupações irregulares caracterizada pelo contraste com as áreas de expansão do vetor sudeste dos investimentos do capital imobiliário e suas novas centralidades - e a zona leste - periferia tradicionalmente ocupada pelas camadas mais desfavorecidas da população formada a partir do estabelecimento de grandes conjuntos habitacionais e que hoje assiste a um processo de incorporação de novas ocupações intersticiais que acabam por introduzir novas complexidades e diferenciações internas. Kowarick circunscreve sua análise a três contextos espaciais tipologicamente definidos: os cortiços nas áreas centrais da cidade, a periferia autoconstruída na zona sul e uma favela na zona oeste da cidade.

A delimitação espacial das análises permite a introdução de um vetor de exploração analítica que em muitos contextos é relegada na utilização da técnica de análise de trajetórias. É justamente esse vetor que pode representar uma substancial contribuição à análise sociourbanística. Soja (1993) já discutia a necessidade de reafirmação do espaço na teoria social crítica, advogando que o reconhecimento da dialética socioespacial passa pela interpretação da organização espacial humana como produto social.

A cidade é, em última instância, experiência espacial que se coloca eloquentemente ao nosso olhar, espaço constituído como produto social sobre o qual o urbanista se debruça em seu ofício de projetação. A compreensão dessa dimensão simbólica e sensorial necessária à elaboração do "plano" exige a incorporação de ferramentas capazes de capturá-las e representá-las. Ainda que, 
como vimos, o método de história de vida e análise de trajetória apresente especificidades procedimentais que o limitam, um conceito derivado apresentado por Telles e Cabanes em sua pesquisa abre frente a novas possibilidades e aplicações em pesquisa sociourbanística: as trajetórias urbanas. Em seu trabalho, estas trajetórias são definidas como

fios de uma descrição da cidade. Trajetórias habitacionais, percursos ocupacionais, deslocamentos cotidianos nos circuitos que articulam trabalho, moradia e serviços urbanos. Três dimensões entrelaçadas nas trajetórias individuais e familiares. Essas formas de mobilidade não são apenas interdependentes, são sobretudo diversas facetas de um único processo de reorganização das condições de existência. Seus eventos precisam, portanto, ser situados nos tempos e espaços em que as histórias se desenrolam. Tempos biográficos organizam trajetórias que individualizam histórias de vida e estão inscritos em práticas situadas em espaços que as colocam em fase com tempos sociais e temporalidades urbanas. (Telles e Cabanes, 2006, p. 69)

A força do conceito reside na possibilidade de intercruzamento entre trajetórias individuais e coletivas orientadas na configuração de espaços sociais. Esses espaços que geralmente escapam às cartografias e se estabelecem na perspectiva relacional do território são elementos constituintes da cidade presente. Permitem incorporar a dimensão do indivíduo enquanto sujeito na noção de cidade e a constituição de novas categorias na análise urbana: fraturas, pontos de tensão, bloqueios, elementos sobre os quais o "plano" deve se apoiar na sua definição programática.

Através das práticas, dos eventos, das inflexões e destinações que singularizam estas essas trajetórias, é possível apreender os movimentos e as tensões do campo social. No curso de suas vidas, indivíduos e suas famílias atravessam espaços sociais diversos, seus percursos passam por diversas fronteiras, e são esses traçados que podem nos informar sobre a tessitura do mundo urbano, seus bloqueios, suas fraturas e pontos de tensão. (Telles e Cabanes, 2006, p. 52)

Ainda que o termo trajetórias urbanas não esteja definido explicitamente dentro de seu trabalho, o estudo de Kowarick é exemplar na construção de uma possível linha de aplicação de análises etnográficas que estabelece vínculo direto com o espaço urbano e sua constituição social e simbólica. O trabalho re- 
vela os percursos vividos por habitantes de cortiços, favelas e periferias com foco nas dimensões de vulnerabilidades socioeconômicas. As narrativas são antecedidas por uma contextualização histórica do processo de formação dessas situações urbanas e seus vínculos com os planos urbanísticos e sucessivos contextos econômicos. Nelas é possível vislumbrar os mapas individuais que cada personagem tem da cidade, as localizações sucessivas por eles habitadas, e o sentido simbólico que atribuem a cada uma delas. Dimensões impossíveis de serem capturadas senão a partir do olhar individual que cada habitante constrói em sua narrativa.

Estes trabalhos são exemplos das possibilidades de aplicação das trajetórias urbanas na construção do que Bourdieu chamou de campo social, um campo, neste caso, cujo sentido se dá por meio da dimensão territorial. O contexto social ganha materialidade espacial e abre a possibilidade de sua incorporação na análise urbanística. Uma perspectiva ainda distante das práticas do urbanista que hoje se ocupa fundamentalmente do espaço em termos físicos orientado por uma visão eminentemente economista que ignora o fato de que modificações nesses espaços implicam mudanças simbólicas aos seus habitantes (Bresciani, 2004).

Por sua vez, nas práticas do campo social pode-se observar um reducionismo da perspectiva espacial, ao se tratar da questão territorial ou urbana como "acidentes de percurso", na análise das situações estudadas ou de intervenção profissional.

As possibilidades que se abrem somente se efetivarão se houver chances de operacionalização de procedimentos que requerem o conhecimento das técnicas disponíveis e até a concepção de outras. As trajetórias sociourbanas podem contribuir neste sentido se implicarem uma agenda de pesquisa que abarque a imbricação entre os territórios e a dinâmica social. Sua operacionalização poderá contribuir para a superação da ambiguidade metodológica preconizada por Argan e pode representar uma chave possível de superação do esquematismo que predomina hoje em urbanismo ou no campo social.

\section{Trajetórias de vida e contribuição para a gestão pública}

No campo social parece prevalecer a lógica da homogeneidade no tratamento territorial, importando mais a definição e os critérios de admissão/inclu- 
são em programas ou serviços e a adequação dos territórios aos mesmos do que um movimento de mão dupla, onde se tem diretrizes políticas e programáticas $\mathrm{e}$, ao mesmo tempo, estratégias de escuta às particularidades das demandas e potencialidades socioterritoriais.

Ou seja, em uma realidade como a brasileira, onde temos um país de dimensão continental e uma herança de desigualdade social, a lógica da homogeneidade na abordagem territorial não contribui para fazer avançar a política pública. Esta lógica desconsidera não somente o conhecimento acumulado do território a respeito de si mesmo, mas também a possibilidade e a própria existência de canais de participação dos cidadãos, antes de tudo, sujeitos de direito. Esses sujeitos que se encontram no chão onde se dá a política não fazem parte da política, mas continuam sendo, como no Brasil colônia, simples assistidos sociais.

Permanecemos, nessa direção, sob a égide da individualização e da culpabilização dos sujeitos pela sua própria condição de pobreza, vulnerabilidade ou risco social.

Ainda que correndo o risco na prática cotidiana de se confinar a dimensão territorial ao seu aspecto administrativo, a política de saúde no Brasil guarda uma experiência ímpar de territorialização a partir da gestão, o que tem iluminado e inspirado o processo de afirmação de outras políticas, como é o caso da política de assistência social. Em tempos de redes digitais e de mundos virtuais, merece destaque a existência de um sistema de saúde baseado no território.

A política de assistência social vem passando por um momento crucial no que tange à sua efetivação como política pública. Nesse processo, que ganha força a partir de 2004 com a aprovação da Política Nacional de Assistência Social e do Sistema Único de Assistência Social — Suas, a experiência do SUS foi e continua sendo referencial.

Importa ressaltar que a Assistência Social, diferentemente da Saúde, ainda passa por um processo de luta pelo reconhecimento de sua identidade como política pública. Por um lado, embora em pleno processo de implantação e implementação nos municípios, o Suas ainda encontra-se em trâmite no Congresso Nacional para ser votado. Por outro lado, permanece ainda o paradigma da assistência social como favor e benemerência, e não como direito na prática e no ideário de gestores, trabalhadores e usuários da política. 
Tal como na Saúde, o território ganha centralidade na política de Assistência Social, sendo uma das diretrizes fundamentais na efetivação do sistema de proteção social. Aqui também a perspectiva territorial se constrói à medida de sua incorporação no modelo de gestão com base municipal e territórios vulneráveis.

Considerando o fato de que em nosso contexto ocorre uma sobreposição de características demográficas das populações em relação às condições de qualidade de vida urbana dos territórios onde se encontram, importa reconhecer os processos produtores de tais condições sobrepostas: população vulnerável vivendo em território vulnerável compondo o fenômeno da vulnerabilidade social.

Segundo Ramos (2005, p. 661-662),

Pode-se dizer que as características socioeconômicas de um determinado território se revelam a partir da composição dos dados populacionais censitários e dos dados territoriais cadastrais. $\mathrm{O}$ fato é que quando se estabelecem estas duas categorias como eixos necessários a uma abordagem socioterritorial surge a necessidade de um novo eixo, perpendicular a estes, contendo a informação sobre a mobilidade tanto espacial como social das populações em seus territórios (Figura 1). As pessoas circulam criando redes de relacionamento em diferentes esferas da vida individual em diferentes escalas territoriais e temporais. Este novo eixo poderia representar uma alternativa para capturar a dimensão relacional revelando a espessura subjetiva do território não evidente nas cartografias tradicionais.

Nessa perspectiva apontada por Ramos haveria que se transpor o binômio dos indicadores populacionais censitários e territoriais cadastrais, buscando capturar o movimento ou a dinâmica que se dá no cotidiano dos territórios analisados, denominado pelo autor de "eixo da mobilidade/conectividade".

É fundamental que essa vertente seja pensada em processos de gestão territorial, no sentido de buscar compreender como se dão as relações nos territórios e entre os territórios, o que permitiria analisar de forma mais aprofundada os fenômenos sociais que se dão ora em movimentos de contiguidade entre territórios, ora em movimentos de ruptura entre os mesmos.

Em se tratando de políticas de proteção social, o entendimento dessas relações nos territórios permite (re)pensar processos de gestão de programas ou 
Figura 1

Eixos de uma representação da realidade socioterritorial

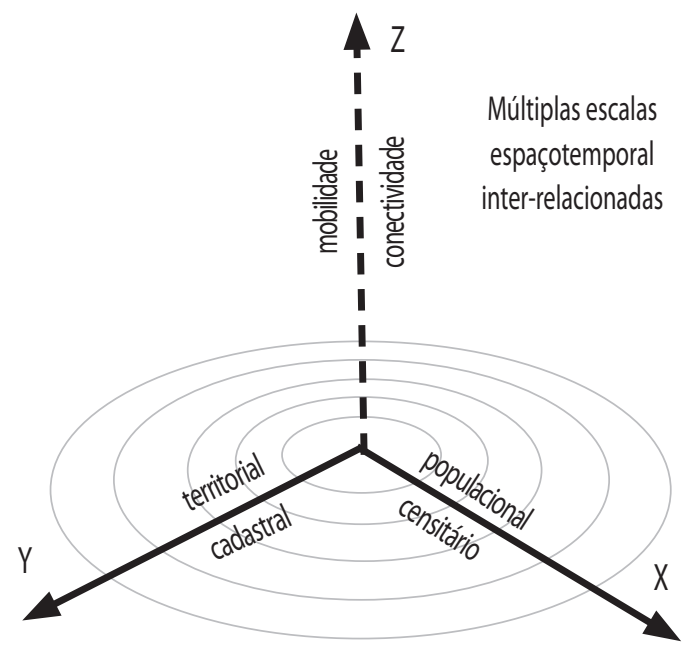

serviços tradicionalmente modelados a partir das configurações relacionais que se dão nesses territórios. E, nesse contexto, uma das questões a ser (re)pensada diz respeito à acessibilidade da população às políticas públicas, que poderia se relacionar ao "eixo da mobilidade/conectividade" proposto por Ramos.

Há de se admitir como, do ponto de vista tecnológico, significativos avanços ocorreram na busca por essa "identificação" de territórios e fenômenos sociais associados, como na área do geoprocessamento. Porém, tais ferramentas e ou técnicas utilizadas no sentido para medir escalas e intensidades também encontram seus limites, como já afirmou Vera Telles:

O fato é que hoje sabemos mais e melhor sobre as características da pobreza urbana, o modo como se distribui nos espaços das cidades e as variáveis que compõem as situações de vulnerabilidade social e exclusão territorial, para usar os termos correntes nos debates atuais. Sabemos mais e melhor sobre a escala dos problemas sociais e os pontos críticos espalhados pela cidade e seus territórios. Mas não sabemos discernir as linhas de força que atravessam as realidades, e o debate parece se dar numa espécie de confinamento do presente imediato, sem 
conseguir romper o círculo de giz traçado pelo tempo curto da gestão das urgências locais. (Telles e Cabanes, 2006, p. 19)

Milton Santos já afirmava que para ele o território enquanto conceito não existiria. "Ele só se torna um conceito utilizável para a análise social quando o consideramos a partir do seu uso, a partir do momento em que o pensamos juntamente com aqueles atores que dele se utilizam" (Santos, 2000, p. 22). A perspectiva de território usado se coloca como emblemático nessa busca por compreender a articulação entre território e condições de vida, pois remete aos aspectos relacionais e, portanto, dinâmicos que perpassam a constituição do território, incluindo aqui as relações de poder.

O ingrediente relacional do poder não pode estar ausente tendo em vista o processo a partir do qual e sobre o qual têm se configurado os territórios brasileiros marcados por disputas econômicas, políticas e sociais. É sobre esse campo que tem se constituído historicamente os nossos territórios e é sobre suas desigualdades produzidas e reproduzidas cotidianamente que se colocam os desafios para a gestão das políticas públicas.

Se o pressuposto aqui delineado é do território usado, relacional e dinâmico, o entendimento sobre as condições de vida nele expressas remete mais à dimensão processual e histórica dos fenômenos sociais produtores dessas situações, e menos à simples caracterização de suas variáveis. Em As metamorfoses da questão social, o autor Robert Castel constrói sua análise sobre o fenômeno da desfiliação social partindo da prerrogativa da não ratificação da ruptura, mas da reconstituição de um percurso (Castel, 1998, p. 26).

Assim, esse eixo de análise, partindo da reconstituição de percurso, permite uma perspectiva aproximativa com a noção de território usado e relacional, pois nem as áreas territoriais nem os próprios fenômenos sociais indicam, a priori, a complexidade que guardam em suas tessituras cotidianas. A ideia de percurso invoca ao fenômeno social analisado a noção de tempo, processos de duração diferenciados, com ritmos próprios, que vão expressar variações de situações aparentemente semelhantes.

Nesse caso, as trajetórias de vidas dos sujeitos caracterizados como igualmente pobres ou vulneráveis passam a indicar peculiaridades diferenciadas nos modos, nos tempos, nas apreensões, nas reações que cada qual construiu. Em- 
bora apresentando as mesmas demandas, trata-se de sujeitos diferentes e, portanto, é possível que suas condições semelhantes exijam respostas distintas. Segundo Castel (1998, p. 26): "Seria preciso reinscrever os déficits em trajetórias, reenviar a dinâmicas mais amplas, estar atento aos pontos de oscilação que geram os estados limites. Procurar a relação entre a situação em que se está e aquela de onde se vem, não autonomizar as situações extremas, mas juntar o que e passa nas periferias com o que acontece em direção ao centro".

Gil Almeida Felix (2008, p. 31), baseado em pesquisa que versou sobre o processo de migração na região da Amazônia oriental, tomou como fonte de análise percursos de indivíduos que se encontravam na condição de pequenos produtores, referenciado na noção de "trajetória" de Bourdieu, a que ele descreveu como "uma série de posições sucessivamente ocupadas por um mesmo agente, num mesmo espaço também submetido a transformações incessantes" Felix (2008, p. 242) ao analisar os deslocamentos desses pequenos produtores no sudeste do Pará, destaca:

Ao que não deixava de saltar aos meus olhos era o sentido que meus interlocutores davam às suas histórias e às suas experiências pretéritas, sugerindo a incorporação de uma determinada noção de vida como trajetória... saber falar sobre a própria vida é um tipo de conhecimento demandado. Valoriza-se "quem tem história pra contar", quem sabe narrar as histórias de seus episódios passados.

Esse conjunto referencial coloca em questão a perspectiva mais disseminada e incorporada dos processos de gestão das políticas púbicas que reside na ideia do território enquanto espaço do fazer administrativo, espaço determinado onde se desenvolvem ações, mais um receptáculo de práticas e decisões normalmente sem vínculos com esse espaço a que foi reduzido o território usado e relacional, recheado de histórias e trajetórias.

\section{Considerações finais}

Propomos, a partir desses referenciais que buscam valorizar menos os pontos de chegada e mais os percursos percorridos, colocar em debate as trajetórias sociourbanísticas enquanto processos essenciais para a compreensão e a 
apreensão da dinâmica socioterritorial presente no cotidiano das populações e dos territórios de intervenção das políticas públicas.

A noção de proximidade dos serviços da residência do cidadão, por exemplo, permeia a lógica de instalação dos mesmos, consolidado na figura de um equipamento físico: posto de saúde, escola, posto policial, Centro de Referência da Assistência Social - Cras. O pressuposto é de que a maior a proximidade do equipamento garante mais acessibilidade por parte do cidadão.

Porém o que se vê no cotidiano das populações é que nem sempre a proximidade garante a qualidade no acesso. Ou seja, a presença do serviço não é garantia que o mesmo funcione e preste um atendimento de qualidade para os cidadãos que o procuram. Exemplo corriqueiro é de famílias que têm filhos em idade escolar e não os matriculam em escola próxima justamente por conhecer a qualidade do serviço prestado. Assim, preferem buscar um serviço de melhor qualidade, ainda que distante.

Esse aspecto da acessibilidade dificultada em função da qualidade do serviço coloca em xeque a noção de proximidade. Ao mesmo tempo, sob o aspecto relacional da constituição territorial, a proximidade traz consigo um ingrediente importante que são as relações de vizinhança enquanto provedoras do fortalecimento de vínculos sociais e mesmo de proteção social. Em se tratando de contextos de vulnerabilidade social, as relações de vizinhança podem exercer uma função vital na própria sustentabilidade das famílias e seus membros.

Esse vetor relacional vem sendo estudado inclusive nas análises sobre a questão da violência e de que maneira essas redes de proximidade são utilizadas como unidades autoprotetivas em territórios que se encontram sob domínio de grupos ligados ao tráfico de drogas e ao crime organizado. No seu estudo já citado sobre as "tramas da cidade", Vera Telles, relembrando os estudos de Alba Zaluar sobre a violência urbana, comenta:

Os padrões de sociabilidade e as regras de reciprocidade que organizam o universo popular são desestabilizados, quando erodidos por disputas, comportamentos, práticas e princípios mafiosos de lealdade que não se restringem ao "negócio do crime", mas transbordam por todos os lados, até porque tudo isso coloca em cena esse "indivíduo-qualquer-como-todo-mundo" que vive por lá, com família, vizinhos, amigos de infância e conhecidos do bar de esquina. (Telles e Cabanes, 2006, p. 102-103) 
Tal transbordamento que atinge o cotidiano de vida relacional dos indivíduos desses territórios que se encontram espalhados pelos "quatro cantos" do nosso país ainda nos parece um tanto desconhecido para as políticas públicas.

No campo da Saúde também se destacam estudos nesse sentido, como problematizado por Simone Santos em seu artigo sobre modelagens em saúde a partir das características de vizinhança, entendendo que: "A estrutura física da vizinhança é condicionada pelas forças sociais. Critérios socialmente definidos contribuem fortemente para a distribuição das pessoas sobre o território e, uma vez estabelecida essa distribuição, a exposição individual pode ser influenciada por fatores sociais (diminuindo ou aumentando os riscos)" (Santos, 2008, p. 173).

Trata-se de um conjunto de experiências em pesquisa sobre as características de vizinhança e seus impactos na saúde, no sentido de capturar por meio de modelos estatísticos - incorporando variáveis demográficas, socioeconômicas, epidemiológicas e o georreferenciamento dos dados — as características inerentes ao contexto social e que não sejam derivadas de informações individuais.

Esse direcionamento traz outro desafio importante para o campo socioassistencial brasileiro, onde ainda encontra-se na fase de aprimoramento um cadastro unificado de seus usuários e no qual são privilegiadas mais as características individuais, e menos os seus vínculos sociais e familiares. Ou seja, permanecemos no eixo cadastral/territorial, onde a relação do indivíduo com o território é simples localização pelo endereço residencial ou referencial.

Nesse sentido, ainda temos muito a avançar em nossos instrumentos de captura e análise do que se passa nos meandros dos nossos territórios e que estão presentes naquelas relações que, talvez pelo fato de serem tão corriqueiras, são reconhecidas como "banais" para os propósitos científicos. Como reforça Simone Santos em seu artigo sobre a presença dos recursos de saúde a serem acessados pelas populações em seus territórios:

É através dos mecanismos de acesso e dos canais pelos quais esses recursos podem ser adquiridos e usados que as condições de vida se expressarão em desigualdades na saúde. A vizinhança não é um depositário passivo de recursos, mas sim uma estrutura relacional que não pode ser concebida independentemente das práticas dos seus residentes em relação a essa estrutura. (Santos, 2008, p. 173) 
Importa considerar esse aspecto relacional apontado por Santos na estrutura da vizinhança mobilizando recursos de saúde e práticas de acessibilidade dos moradores, que certamente ultrapassa o campo da saúde. Trata-se dos mesmos territórios onde outros agenciamentos públicos e privados permeiam o cotidiano de cidadãos e suas famílias, compondo o mosaico de vizinhança. Resta saber como tem se configurado tal mosaico, a ponto de produzir ou não acessibilidade, garantir ou não proteção social, fortalecer ou não vínculos sociais.

Nossas estratégias de gestão talvez se encontrem ainda distantes dessa dinâmica relacional cotidiana, pois se ocupam mais das respostas às emergências e urgências demandadas localmente. A vigilância em saúde tem representado importante avanço na perspectiva do planejamento/monitoramento/avaliação da política, pois hoje se considera parte essencial do processo de gestão, e não uma área à parte ou um conjunto de informações isoladas, simples acessório da política.

Essa noção da vigilância em saúde também vai contribuir para a proposta da Vigilância Social no Suas, que se encontra em processo de incorporação nos diferentes níveis de gestão, talvez ainda concebida mais como instrumento, e não necessariamente como parte da gestão, tal como está delineado na Política Nacional da Assistência Social, onde "os serviços socioassistenciais no Suas são organizados segundo as seguintes referências: vigilância social, proteção social e defesa social e institucional. (Brasil, 2004, p. 24)

Um dos principais desafios do Suas junto aos territórios locais de gestão reside justamente no (re)conhecimento de suas particularidades a partir de sua dinâmica, e não somente de suas estatísticas oficiais. Embora até mesmo esses indicadores locais ainda se revelem pouco acessíveis a um número significativo dos municípios, há que se avançar também do ponto de vista da captura das informações que sejam reveladoras do que se passa no cotidiano de gestão da Assistência Social nesses territórios.

O diagnóstico socioterritorial ainda é uma realidade a ser conquistada e incorporada em âmbito nacional pelo Suas, na perspectiva da construção de um sistema de vigilância social que faça sentido e contribua para os processos de gestão dos territórios.

O fato é que no contexto brasileiro de formação desses territórios, constituídos sob a égide elitista e patrimonialista, permanece ainda o desafio do re- 
conhecimento dos territórios reais ou da cidade real pelas próprias políticas públicas, que ainda encontram dificuldades em transpor os muros da cidade legal, dos territórios oficiais, dos quais não fazem parte os sem-teto, sem endereço, sem-terra, sem identidade.

Assim, não basta a dimensão territorial da política pública, caso ela permaneça confinada institucionalmente sem conseguir ir além do aspecto administrativo. Faz-se necessário, essencialmente, a incorporação do território vivo e vivido, trazendo à tona os aspectos coletivo e público a se fortalecer nas mediações das práticas sociais cotidianas desenvolvidas pelos diferentes agenciadores da própria política pública. Aqui, o (re)conhecimento sobre as trajetórias de vida dos chamados "usuários" das políticas públicas poderia representar uma chave importante para processos da gestão pública onde os cidadãos encontrem-se na centralidade do interesse e prevaleça a conexão indivisível entre os campos urbano e social.

\section{Recebido em mar./2011 n Aprovado em abr./2011}

\section{Referências bibliográficas}

ARGAN, G. C. Arte moderna. São Paulo: Companhia das Letras, 1992. 693p. . Urbanismo, espaço e ambiente. In: . História da arte como história da cidade. São Paulo: Martins Fontes, 1993. p. 212.

AUGÉ, M. Não-lugares: Introdução a uma antropologia da supermodernidade. Campinas: Papirus, 1994. 111p.

BOURDIEU, Pierre. A ilusão biográfica. In: Ferreira, Marieta (Org.). Usos e abusos da história oral. Rio de Janeiro: Editora da Fundação Getúlio Vargas, 1996. p. 183-91.

BRASIL. Ministério do Desenvolvimento Social e Combate à Fome. Política Nacional de Assistência Social. Brasília, 2004.

BRESCIANI, M. S. A cidade: objeto de estudo e experiência vicenciada. Revista Brasileira de Estudos Urbanos e Regionais, Florianópolis, v. 6, n. 2, 2004.

BURGESS, E. W. The growth of the city: an introduction to a research project. Chicago: The University of Chicago Press, 1925. p. 47-62. Tradução brasileira por Olga Dória. 
O crescimento da cidade: introdução a um projeto de pesquisa. Universidade de São Paulo, 1970. p. 16-41.

. The growth of the city: an introduction to a research project. Chicago: The University of Chicago Press, 1925. p. 47-62.

CASTEL, Robert. As metamorfoses da questão social. Petrópolis: Vozes, 1998.

DAMON, Julien. Questions sociales et questions urbaines. Paris: PUF, 2010.

DI LEONARDO, M. Oral history as ethnographic encounter. The Oral History Review, v. 15, p. 1-20, 1987.

DUBAR, Claude. Trajetórias sociais e formas identitárias: alguns esclarecimentos conceituais e metodológicos. Educação \& Sociedade, Campinas, n. 62, p. 13-30, abr. 1998.

FELIX, Gil Almeida. O caminho do mundo: mobilidade espacial camponesa numa região da Amazônia oriental. Rio de Janeiro: Editora da UFF, 2008.

KOWARICK, L. Viver em risco. Sobre a vulnerabilidade socioeconômica e civil. São Paulo: Editora 34, 2009. 320p.

MELAZZO, Everaldo; GUIMARÃES, Raul Borges. Exclusão social em cidades brasileiras. São Paulo: Editora Unesp, 2010.

MENDOZA, E. S. G. Donald Pierson e a escola sociológica de Chicago no Brasil: os estudos urbanos na cidade de São Paulo (1935-1950). Sociologias, Porto Alegre, ano 7 , n. 14, p. 440-470, jun./dez. 2005.

MONTAGNER, M. A. Trajetórias e biografias: notas para uma análise bourdieusiana. Sociologias, Porto Alegre, ano 9, n. 17, p. 240-264, jan./jun. 2007.

NOGUEIRA, Oracy. Pesquisa social: introdução às suas técnicas. São Paulo: Editora Nacional, 1975. p. 137-148.

QUEIROZ, Maria Isaura Pereira de. Variações sobre a técnica de gravador no registro da informação viva. São Paulo: T. A. Queiroz, 1991.

RAMOS, Frederico Roman. Cartografias sociais como instrumentos de gestão social: a tecnologia a serviço da inclusão social. RAP - Revista Brasileira de Administração, Rio de Janeiro, v. 39, n. 3, p. 655-69, maio/jun. 2005.

ROLNIK, Raquel. A cidade e a lei. 2. ed. São Paulo: Fapesp/Studio Nobel, 1999.

SANTOS, Milton. Território e sociedade entrevista com Milton Santos. São Paulo: Fundação Perseu Abramo, 2000. 
SANTOS, Simone M. Desigualdades socioespaciais em saúde: incorporação de características de vizinhança nos modelos de determinação em saúde. In: BARCELLOS, Christovam (Org.). A geografia e o contexto dos problemas de saúde. Rio de Janeiro: Abrasco, 2008. p.165-192.

SOJA, E. S. Geografias pós-modernas: a reafirmação do espaço na teoria social crítica. Rio de Janeiro: Jorge Zahar, 1993.

TELLES, V.; CABANES, R. (Org.). Nas tramas da cidade: trajetórias urbanas e seus territórios. São Paulo: Humanitas, 2006.

Weber, R. Relatos de quem colhe relatos: pesquisa em história oral e ciências sociais. Dados, v. 39, n. 1, p. 163-82, 1996.

. Relatos de quem colhe relatos: pesquisa em história oral e ciências sociais. Dados, v. 39, n. 1, p. 163-82, 1996. 